\title{
The Effect of Local Tramadol Injection in Post Appendectomy Pain
}

\author{
Alireza Khazaei ${ }^{1}$; Farshid Arbabi Kalati ${ }^{2,}$; Soheil Borumand ${ }^{1}$; Reza Rooshanravan ${ }^{1}$ \\ ${ }^{1}$ Department of Surgery, Zahedan University of Medical Sciences, Zahedan, IR Iran \\ ${ }^{2}$ Department of Radiotherapy, Zahedan University of Medical Sciences, Zahedan, IR Iran \\ *Corresponding author: Farshid Arbabi Kalati, Department of Radiotherapy, Zahedan University of Medical Sciences, Zahedan, IR Iran. E-mail: farshidarbabi@gmail.com
}

Received: May 11, 2013; Accepted: September 24, 2013

\begin{abstract}
Background: Tramadol is a weak synthetic opioid with an effective analgesic result. This medicine has both systemic and local anesthetic effects on peripheral nerve system.

Objectives: The purpose of this study is to compare post-appendectomy analgesic effect of subcutaneous injection of tramadol with normal saline.

Patients and Methods: This double blind study was conducted on 60 patients over 15 years old, who were randomly divided in two equal groups, i.e. tramadol and normal saline. After repairing fascia in appendectomy, $100 \mathrm{mg}$ of tramadol that was diluted up to $10 \mathrm{~mL}$ and 10 $\mathrm{mL}$ normal saline were used for subcutaneously injection around the surgical wound in experimental and control groups, respectively. Then, the intensity of pain was recorded in the recovery room, and 6 and 24 hours after operation, based on NRS. In addition, number of petidine (with a dosage of 25 milligram) administered in the same period, in case of severe and moderate pain, was recorded. At the end, the intensity of pain during the mentioned time and the average use of petidine in two groups were compared.

Results: The average of severe pain in recovery time ( $3.08 \pm 1.44$ versus $5.36 \pm 2.02), 6$ ( $3.36 \pm 1.22$ versus $5.36 \pm 1.38$ ) and 12 (2.08 \pm 0.76 versus $3.08 \pm 1.15)$ hours after operation was lower in tramadol group $(\mathrm{P}=0.0001)$. Moreover, the amount of consumed petidine in the same period of time showed a clear reduction $(\mathrm{P}<0.05)$.

Conclusions: Subcutaneous injection of tramadol is an appropriate choice for reduction of post-appendectomy pain and decreasing need for potent narcotic painkillers. This treatment method can decrease side effects of using potent narcotics after appendectomy.
\end{abstract}

Keywords: Appendectomy; Tramadol; Subcutaneous Injection; Postoperative Pain

\section{Background}

Acute appendicitis with 8.6 and $6.6 \%$ of prevalence among men and women, in turn, is a very common disease [1-3]. Generally, 7\% of total population undergoes appendectomy [2]. Something between thirty to $40 \%$ of patients, undergoing abdominal surgery, suffers from moderate to severe pain [4]. The amount of pain felt by patient is affected by several variable including type and duration of operation, type of anesthesia and anesthetic used, and mental and emotional status of the patient [5]. For decreasing postoperative pain different methods and medicines are used. The use of systemic opioids alone is not enough for postoperative analgesic effect. It can be associated with side effects such as nausea, vomiting, constipation, itching, and respiratory and cardiac suppression [6, 7]. In addition, non-steroidal antiinflammatory drugs (NSAIDs) may cause skin reaction, and renal (analgesic nephropathy) and digestive (peptic ulcers and their effects) complications. Therefore, it is attempted to relieve post-operative pain by using more accessible and cheaper methods, and of course with less side effect. Local injection techniques are one of those methods. In this technique, local anesthetics and weak opioids, like tramadol, have been examined [8-13]. Tramadol is a medicine with central effect, which has been effective in reduction of moderate and severe pains. In clinical and laboratory studies, its local analgesic and anesthetic, in addition to its systemic, effects on peripheral nerves and spinal cord have been proven [7-24]. Tramadol is well tolerated by patients. In comparison with morphine and petidine, tramadol causes much less respiratory depression. Cardiac depression, dizziness, and light headedness are less likely to happen after using tramadol than morphine. Tramadol addiction and abuse is much less than morphine. The only important side effect of Tramadol is nausea and vomiting that can be prevented by taking anti-nausea drugs such as metoclopramide [25-27]. There is no standard method for local infiltration around the wound in operations such as appendectomy. Despite the use of different medicines for local anesthesia, but the variety of them and their practicing methods has prevented from arriving at a general conclusion $[5,28,29]$. In the face of pharmacologic features of tramadol, a few numbers of articles have addressed this medicine.

Copyright (C) 2015, Zahedan University of Medical Sciences. This is an open-access article distributed under the terms of the Creative Commons Attribution-NonCommercial 4.0 International License (http://creativecommons.org/licenses/by-nc/4.0/) which permits copy and redistribute the material just in noncommercial usages, provided the original work is properly cited. 
Khazaei A et al.

\section{Objectives}

Therefore, we aim here to investigate the post-appendectomy anesthetic effect of tramadol in comparison with placebo.

\section{Patients and Methods}

In this double-blind randomized clinical trial a total of thirty samples were assigned to each group, based on previous relevant investigations. The aim was to survey local analgesic effect of tramadol on the basis of difference from the mean using an alpha level of $5 \%$ and beta level of $80 \%$. The treatment protocol for patients was discussed and approved in Ethics committee of Zahedan University of Medical Sciences. All appendectomy-candidates with simple acute appendicitis were informed well about the project. They then were assigned into research groups after completing informed consent letter by the patients, their parents, or their legal guardians, and in case of being eligible for inclusion criteria. The sampling continued to reach the desired size, based on the previous blocks randomization design. Inclusion criteria included: appendectomy-candidates with non-perforated simple appendicitis that underwent appendectomy surgery, under general anesthesia and McBurney's short diagonal incision, in Ali-Ibn-Abi-Taleb (a.s.) and Khatamal-Anbia (PBUH) Hospitals in Zahedan. Patients with at least one of the following conditions were excluded from the study: under 15 years old, the existence of underlying conditions like cardiovascular diseases, pregnancy, diabetes, liver disease, respiratory disease, a history of previous abdominal surgery, complicated appendicitis, drug addiction, non-McBurney incision appendectomies, appendectomy performed with non-general anesthesia, taking analgesic medication by the patient six hours before surgery, and intendancy of the patient to participate. All patients were transferred to the operation room after primary measures such fluid therapy and taking prophylactic antibiotics, and laid in supine position on operating room bed. None of the patients had a urinary catheter and nasogastric tube. In addition, the operations performed under conduction of similar anesthetic technique, i.e. injection into peripheral vein of the forearm. Before skin closure and after closing the outer diagonal fascia, anesthesia technicians provided surgeon with a $10 \mathrm{~mm}$ syringe filled by normal saline or a same one filled with $100 \mathrm{mg}$ tramadol, diluted by saline up to $10 \mathrm{~mL}$, in sterile condition. Both of prepared anesthetics were exactly similar with respect to color and transparency. It should be noted that whole the process was done based on previous randomization to intervention and control groups. After washing the wound with normal saline, the surgeon, who was unaware of the content of the syringes, injected them across the length and sides of the wound. Then, the skin was repaired using separate 0 - 3 nylon sutures $3 / 0$ and dressed. The patients had liquid diet started eighteen hours after surgery followed by normal diet twenty-four hours after operation. They were discharged at the second day. The level of pain was evaluated in recovery time, and six and twenty-four hours after operation using Numeric Rating Scale (NRS). After twenty-four hours, the number of $25 \mathrm{mg}$ dosages injected was recorded by referring to nursing reports. For the purpose of uniformity and reducing confounding factors no analgesics, except petidine, was injected. In addition, oral or rectal analgesic medications were not administered. All patients were given the same antibiotic administration strategy for 24 hours. For comparing average pain intensity between the groups and average petidine dosage consumed in each group, t-test was employed.

\section{Results}

In this study, sixty patients were examined, out of which thirty-four and twenty-six subjects were men and women, respectively. Control group consisted of eighteen men and twelve women, and experimental group included sixteen men and fourteen women. The average age of the patients was $25.6 \pm 8.1$ years (with $26.48 \pm 8.4$ and $24.72 \pm 7.8$ years in experimental and control groups, respectively). To obtain frequency difference of the genders in the groups, ${ }^{2}$ test was used and showed no statistically significant difference. In addition, t-test was employed for drawing comparison between average ages of both groups. Similarly, no significant difference was observed. That is, both groups were similar at the beginning of the study by sex and age. The average intensity of pain of $5.36 \pm 2.02$ and $3.08 \pm 1.44$ was obtained at recovery time, indicating a significant pain reduction in the tramadol group $(\mathrm{P}=0.0001)$. The average intensity of pain at the sixth hour after operation was 5.36 \pm 1.38 in control group, and $3.36 \pm 1.22$ in tramadol group, indicating significant reduction in tramadol group $(\mathrm{P}=$ 0.0001 ). The average intensity of pain at the 24 th hour after operation was $3.08 \pm 1.15$ in control group, and $2.08 \pm 0.76$ in tramadol group, indicating significant reduction in tramadol group. Relevant to petidine doses number prescribed to tramadol and control groups during twenty-four hours, i.e. $0.76 \pm 0.83$ and $1.56 \pm 0.65$ in average respectively, indicated less need for petidine in tramadol group during twenty-four hours after operation $(\mathrm{P}=0.0001)$, Table 1 .

\begin{tabular}{lccc}
\hline Table 1. Comparison Between Average Intensity of Pain in Both Groups at Different Times & \\
\hline Average intensity of pain & Tramadol Group & Control Group & P-Value \\
\hline Recovery & $3.08 \pm 1.44$ & $5.36 \pm 2.02$ & 0.0001 \\
After 6 hours & $3.36 \pm 1.22$ & $5.36 \pm 1.38$ & 0.0001 \\
After 24 hours & $2.08 \pm 0.76$ & $3.08 \pm 1.15$ & 0.0001 \\
\hline
\end{tabular}


Khazaei A et al.

\section{Discussion}

The results from this study strongly indicate pain reduction in tramadol group at three investigated points of time. In addition, the amount of consumed petidine was half in tramadol group. Among a few numbers of studies on analgesic effect of tramadol injection, Demiraran's, can be noted. He divided seventy-five children, with a history of herniotomy surgery, into three equal groups. The first, second, and third groups received subcutaneous injection of tramadol $(2 \mathrm{mg} / \mathrm{kg})$, bupivacaine $(0.25 \%)$, and intramuscular injection of tramadol $(2 \mathrm{mg} / \mathrm{kg})$, respectively. Then, pain was measured one, four, eight, twelve, and twenty-four hours after injections. The average intensity of pain at one, four, and eight hours after injection was clearly lower in subcutaneous tramadol group than two others [30]. However, the findings of this study are in consistent with ours, but some differences exist in practicing methods. In this study, bupivacaine and intramuscular tramadol were used in control group, while we used normal saline. It can be concluded from the above study that as intensity of pain in subcutaneous tramadol group was lower than in intramuscular tramadol group, so in addition to systemic analgesic effect, tramadol had an anesthesic and even anti-inflammatory effect. This anti-inflammatory effect has been suggested in other studies $[9,29]$. In a study, published in 2004 , forty patients undergoing same-day surgery were divided into two equal groups. The first and second groups received local anesthetic with $1 \mathrm{mg} / \mathrm{kg}$ subcutaneous lidocaine and $2 \mathrm{mg}$ / $\mathrm{kg}$ subcutaneous tramadol, respectively, and then they underwent same-day surgery. The level of operative pain was recorder in a fifteen minutes time intervals routine based on Visual Analog Scale (VAS). The results indicated that the difference in the intensity of pain was intangible at 15 th and 30th minutes of the operations. However, only $10 \%$ of tramadol group needed analgesic medication during the 24 hours after surgery, this number was 50\% in lidocaine group. When the amounts of consumed analgesic medication were compared, it was significantly less in tramadol group [8]. This study showed that tramadol provided postoperative local anesthesia equal to lidocaine. Moreover, tramadol extended the pain-free period after operation and decreased the need for postoperative analgesia. Regarding that general anesthesia is administered in our study, so the effect of local anesthesia during operation cannot be investigated. However, the results of this study regarding postoperative pain relief and decreased need for analgesia in tramadol group conform to ours. In a study by Khajavi [12], sixty patients, undergoing pyelolithotomy, were randomly divided into two equal groups of thirty subjects. One of them was given postoperative intravenous injection, and the other received subcutaneous tramadol injection. The degree of the pain was recorded at the 30th min and 60th min after transferring into recovery room, based on VAS. The results showed significant pain-relief in subcutaneous tramadol injec- tion group. In addition, the time span before taking first postoperative dose of meperidine was significantly longer. Moreover, the total amount of meperidine consumed over 24 hours considerably decreased in subcutaneous tramadol group, indicating local anesthetic effect of tramadol in addition to its systemic analgesic effect [12]. These researches concluded that subcutaneous injection of tramadol decreases the need for opioids after operation, which per se supports our findings. However, above study somehow differs from ours in terms of research method and control groups, but the results indicate sufficient analgesic and anesthetic effects of tramadol and decreased need for opioid and non-opioid analgesics after operation. In some investigations, lidocaine was used as an alternative drug to normal saline, and in some other studies intramuscular tramadol was employed. However, the results indicate that subcutaneous injection of tramadol has superiority over systemic injection. In addition, it was indirectly proven that local anesthetic effect of tramadol at the beginning is not less than other local anesthetics such as lidocaine. According to the findings of this study and in comparison with that of other studies, it has been found that subcutaneous injection of tramadol causes post-appendectomy pain relief. Moreover, it decreases the postoperative need for opioid anesthetics. Therefore, subcutaneous injection of tramadol can be employed as a useful post-appendectomy analgesic. As a final point, researches recommend a similar study in comparative form between the use of tramadol and other local anesthetics in appendectomy incision. In addition, regarding a limited number of studies on tramadol, the effect of it on other areas of surgery can be surveyed.

\section{Acknowledgements}

This article is the result of thesis No.489 approved by Research Deputy of Medical Faculty of Zahedan University of Medical Sciences.

\section{Authors' Contributions}

All authors had equal role in design, work, statistical analysis and manuscript writing.

\section{Funding/Support}

Zahedan University of Medical Sciences and Health Services.

\section{References}

1. Korner H, Sondenaa K, Soreide JA, Andersen E, Nysted A, Lende $\mathrm{TH}$, et al. Incidence of acute nonperforated and perforated appendicitis: age-specific and sex-specific analysis. World J Surg. 1997;21(3):313-7.

2. Addiss DG, Shaffer N, Fowler BS, Tauxe RV. The epidemiology of appendicitis and appendectomy in the United States. Am J Epidemiol.1990;132(5):910-25.

3. Korner H, Soreide JA, Pedersen EJ, Bru T, Sondenaa K, Vatten L. Stability in incidence of acute appendicitis. A population-based longitudinal study. Dig Surg. 2001;18(1):61-6. 
4. Almeida OJ, Val-Gallas JM, Rizk B. Appendectomy under local anaesthesia following conscious pain mapping with microlaparoscopy. Hum Reprod.1998;13(3):588-90.

5. Lowenstein L, Zimmer EZ, Deutsch M, Paz Y, Yaniv D, Jakobi P. Preoperative analgesia with local lidocaine infiltration for abdominal hysterectomy pain management. Eur J Obstet Gynecol Reprod Biol. 2008;136(2):239-42.

6. Cheever KH. Pain, analgesic use, and morbidity in appendectomy patients. Clin Nurs Res. 1999;8(3):267-82.

7. Radbruch L, Grond S, Lehmann KA. A risk-benefit assessment of tramadol in the management of pain. Drug Saf.1996;15(1):8-29.

8. Altunkaya H, Ozer Y, Kargi E, Ozkocak I, Hosnuter M, Demirel CB, et al. The postoperative analgesic effect of tramadol when used as subcutaneous local anesthetic. Anesth Analg. 2004;99(5):1461-4.

9. Gercek A, Eti Z, Gogus FY, Sav A. The analgesic and anti-inflammatory effects of subcutaneous bupivacaine, morphine and tramadol in rats. Agri. 2004;16(3):53-8.

10. Jensen SI, Andersen M, Nielsen J, Qvist N. Incisional local anaesthesia versus placebo for pain relief after appendectomy in children--a double-blinded controlled randomised trial. Eur J Pediatr Surg. 2004;14(6):410-3.

11. Lohsiriwat V, Lert-akyamanee N, Rushatamukayanunt W. Efficacy of pre-incisional bupivacaine infiltration on postoperative pain relief after appendectomy: prospective double-blind randomized trial. World J Surg. 2004;28(10):947-50.

12. Khajavi MR, Aghili SB, Moharari RS, Najafi A, Mohtaram R, Khashayar P, et al. Subcutaneous tramadol infiltration at the wound site versus intravenous administration after pyelolithotomy Ann Pharmacother. 2009;43(3):430-5.

13. Negro S, Martin A, Azuara L, Sanchez Y, Barcia E. Compatibility and stability of ternary admixtures of tramadol, haloperidol, and hyoscine N-butyl bromide: retrospective clinical evaluation. J Palliat Med. 2010;13(3):273-7.

14. Flohe L, Arend I, Cogal A, Richter W, Simon W. [Clinical study on the development of dependency after long-term treatment with tramadol (author's transl)]. german. Arzneimittelforschung. 1978;28(1a):213-7.

15. Schenck EG, Arend I. [The effect of tramadol in an open clinical trial (author's transl)]. german. Arzneimittelforschung 1978;28(1a):209-12.

16. Fassolt A. [The analgesic effectiveness of Tramal (tramadol) 100 $\mathrm{mg}$ for postoperative wound pain (author's transl)]. german. Sch weiz Rundsch Med Prax 1981:70(10):435-40.

17. Gunther W. [The use of tramadol-HCl (Tramal) as adjuvant in regional anaesthesia. Clinical report (author's transl)]. german. Reg Anaesth. 1982;5(1):20-1.

18. Lehmann KA, Horrichs G, Hoeckle W. [The significance of tramadol as an intraoperative analgesic. A randomized doubleblind study in comparison with placebo]. german. Anaesthesist. 1985;34(1):11-9.

19. Fu YP, Chan KH, Lee TK, Chang JC, Daiy YP, Lee TY. Epidural tramadol for postoperative pain relief. Ma Zui Xue Za Zhi.1991;29(3):648-52.

20. Chen TP, Hwang TI, Yu CT, Yang CR, Chang CL, Change CH, et al. [Analgesic effect of tramadol HCL in ESWL]. chinese. Zhonghua Y Xue Za Zhi (Taipei).1993;51(2):134-7.

21. Sunshine A. New clinical experience with tramadol. Drugs 1994;47 Suppl 1:8-18.

22. Katz WA. Pharmacology and clinical experience with tramadol in osteoarthritis. Drugs. 1996;52 Suppl 3:39-47

23. Cai J, Guo QL, Zou WY. [Clinical anesthetic effects of epidura ropivacaine with tramadol]. chinese. Zhong Nan Da Xue Xue Bao Yi Xue Ban. 2004;29(2):218-20.

24. dos Santos TO, Estrela TG, de Azevedo VL, de Oliveira OE, Oliveira GJ, Figueiredo Gda S. Intravenous and subcutaneous tramado for inguinal herniorrhaphy: comparative study. Rev Bras Anestesiol. 2010;60(5):522-7.

25. Pang WW, Wu HS, Lin CH, Chang DP, Huang MH. Metoclopramide decreases emesis but increases sedation in tramadol patientcontrolled analgesia. Can J Anaesth. 2002;49(10):1029-33.

26. Scott LJ, Perry CM. Tramadol: a review of its use in perioperative pain. Drugs. 2000;60(1):139-76.

27. Pang WW, Wu HS, Tung CC. Tramadol $2.5 \mathrm{mg}$ x kg(-1) appears to be the optimal intraoperative loading dose before patient-controlled analgesia. Can J Anaesth. 2003;50(1):48-51.

28. Kaki AM, Al Marakbi W. Post-herniorrhapy infiltration of tramadol versus bupivacaine for postoperative pain relief: a randomized study. Ann Saudi Med. 2008;28(3):165-8.

29. Kraychete DC, Sakata RK, Issy AM, Bacellar O, Jesus RS, Carvalho EM. Proinflammatory cytokines in patients with neuropathic pain treated with Tramadol. Rev Bras Anestesiol. 2009;59(3):297-303.

30. Demiraran Y, Ilce Z, Kocaman B, Bozkurt P. Does tramadol wound infiltration offer an advantage over bupivacaine for postoperative analgesia in children following herniotomy? Paediatr Anaesth. 2006;16(10):1047-50 